La necesaria reconciliación entre Ciencia Política y Ciencia Jurídica. Apuntes sobre la Clase Magistral de Guillermo O'Donnell: "Acerca de la Ley, el Estado y la Democracia"

The necessary reconciliation between Political Science and Legal Science. Notes on the Master Class by Guillermo O'Donnell: "On Law, State and Democracy"

\title{
Gloria Trocello
}

Gloria Trocello es investigadora y Profesora Titular Ordinaria de Ciencias Políticas en el Departamento de CS Económico-Sociales de la Universidad Nacional de San Luis, Argentina.

E-mail: gtrocello@hotmail.com

\section{resumen}

Este texto recupera la conferencia dictada por Guillermo O'Donnell al obtener el Grado Académico "Doctor Honoris Causa" por la Universidad Nacional de San Luis, titulada "Acerca de la Ley, el Estado y la Democracia". En la misma, se condensan algunas recomendaciones vinculadas a su producción de los últimos tiempos que destacan la importancia de la vigencia del derecho para la existencia de un estado democrático. Imbricado en este problema reflexiona de una manera muy crítica respecto de lo que denomina "el divorcio entre la ciencia política y la ciencia jurídica”.

\section{palabras clave}

Ciencia Política / Ciencias Jurídicas / Estado / Ley / Estado de Derecho / régimen democrático

\section{summary}

This text reviews the lecture by Guillermo O' Donnell to obtain the academic degree "Doctor Honoris Causa" by the National University of San Luis, with the exposition "About the Law, the State and Democracy". In it, the author condenses some recommendations related to the rule of law and the existence of democratic state. Embedded in this issue, it reflects a very critical of what he calls "the divorce between political science and legal science".

\section{keywords}

Political Science / Legal Sciences / State / Law / Rule of law / democratic regime 
Mi homenaje cotidiano a Guillermo O'Donnell se traduce en enseñar sus textos a los alumnos en la Universidad Nacional de San Luis, vinculando sus aportes con mi quehacer cotidiano como profesora e investigadora que por más de veinticinco años ha estudiado las zonas marrones de la democracia. Esto es porque vivo en una zona marrón, porque sufro las instituciones informales y las deformaciones de un estado patrimonializado; y además porque -y quizás por ello- fui siempre su silenciosa discípula, que leyó de manera incansable sus textos para encontrar respuestas a mi realidad provincial. Me sentí sensiblemente interpretada cuando, hace ya dos décadas, él llamaba la atención respecto de dos premisas tácitas de la teoría democrática contemporánea que no se daban en América Latina. Una es que la legalidad estatal se extiende homogéneamente sobre el territorio, y otra que el régimen nacional democrático supone que también lo son los regímenes provinciales y locales (O’Donnell, 1993). ${ }^{1}$ Esta preocupación, que orientó casi toda su obra, lo llevó a hacer la siguiente recomendación: "no se deben importar acríticamente - premisas implícitas incluidas-teorías elaboradas en y a partir de la experiencia de los países centrales”. Ello es así, además, porque: "son también magnos problemas prácticos, que afectan severamente la posibilidad de expandir nuestras democracias y, por supuesto, la calidad de las mismas" (O’Donnell, 1997).

Guillermo O'Donnell tuvo la generosidad de opinar sobre mi aporte para comprender estas zonas marrones ${ }^{2}$ y me recomendó indagar la relación entre el estado y sistema jurídico provincial para descubrir deslizamientos autoritarios. Y ello se debía a que, según su opinión "el problema San Luis no era solo un problema de régimen neopatrimonialista sino de falta de estado democrático". ${ }^{3}$ Conocedora de su interés por esta realidad lo invité a conocer mi provincia. Aceptó gustoso, y en marzo de 2010 nos visitaron con Gabriela Ippolito, su esposa.

La Universidad Nacional de San Luis decidió otorgarle la máxima distinción ${ }^{4}$ : el Grado Académico de "Doctor Honoris Causa". Se estableció que la entrega del título coincidiera con el Acto Inaugural de las Carreras en Ciencias Jurídicas ${ }^{5}$, y él dispuso que su Clase Magistral se titulara "Acerca de la Ley, el Estado y la Democracia". En la misma, se condensan algunas recomendaciones vinculadas a su producción de los últimos tiempos que destacan la importancia de la vigencia del derecho para la existencia de un estado democrático. Imbricado en este problema reflexiona de una manera muy crítica respecto de lo que denomina "el divorcio entre la ciencia política y la ciencia jurídica".

Creo que el compartir esta clase magistral ${ }^{6}$-que es un aporte más de su riquísimo legado- puede ser una forma original y provechosa de colaborar en un homenaje como el que le realiza la prestigiosa revista Temas y Debates. A fin de cumplir con las recomendaciones de edición relativas al espacio asignado, voy a destacar los temas centrales intentando resumir lo que considero son los aportes teóricos más conocidos -y que él sintetizaba en la exposición-, dejando textual lo que a mi entender es lo más importante: sus recomendaciones. Sí, deseo enfatizar lo que se reiteró en toda la conferencia, y en diversos momentos: la necesidad de superar ese divorcio entre ciencia política y ciencia jurídica. ${ }^{7}$ 


\section{Una clase desde una universidad pública ${ }^{8}$}

El 9 de marzo de 2010 el Aula Magna del Centro Universitario de Villa Mercedes de la Universidad Nacional de San Luis estaba colmada. Además, en aulas contiguas se reproducía lo que allí ocurría a través de video-conferencias. Estaban presentes, en la que sería su primera clase, los ingresantes a las carreras jurídicas, la mayoría muy jóvenes. Asistieron también muchos egresados de otras carreras que estudiaron asignaturas de ciencias políticas y docentes e investigadores que seguían su producción y deseaban conocerlo, además de periodistas y público; todos expectantes para escuchar su conferencia.

Que se iniciara el dictado de carreras jurídicas (abogacía, procurador y técnico en asistencia jurídica) con una clase magistral de Guillermo O'Donnell no era una cuestión fortuita sino una coincidencia buscada y cargada de simbolismo. Se trataba de alguien que -en origen- era abogado, había fundado la ciencia política latinoamericana, y especialmente se había dedicado con empeño a descifrar los problemas de nuestras democracias.

$\mathrm{Al}$ ingresar Guillermo O'Donnell al Aula Magna, como también al formar parte de la Mesa Académica los aplausos parecían no querer acabar, y él acompañaba su turbación con una sonrisa, mientras agradecía al auditorio. Sentada en la primera fila, su esposa Gabriela seguía atenta sus emociones y sus tiempos. Luego de las cuestiones protocolares, los discursos y la entrega del título y la medalla, tuve el honor de presentarlo.

Guillermo O'Donnell agradeció las múltiples formas de admiración y afecto y las sintetizó diciendo que para él era un "momento que uno guarda en su corazón para siempre", que habría de vincularlo especialmente a que la distinción provenía (en sus palabras) "de una universidad que no solo es una universidad del estado, sino que es una universidad, que es y quiere ser pública, en el sentido de su vocación de proveer a las diversas localidades provinciales y nacionales un enorme bien público como era ... la creación de nuevas carreras". Volvió sobre ello manifestando que deseaba contar "una pequeña historia personal"; y dijo: "empieza conmigo, recibiéndome de abogado con mucho orgullo, soy un producto de una universidad pública nacional, de la UBA, es algo que me marca... como un entusiasta, amigo y colaborador de estas universidades públicas. Cuando me inicié en la abogacía no había ninguna carrera universitaria formalizada en ciencia política y en sociología tampoco; y empecé por el derecho público, estudié mucho, pero me pareció un poco aburrido, porque consistía básicamente en el estudio comparado de constituciones y de leyes sin entrar mucho en el estudio de los comportamientos o de las conexiones concretas de esta legislación comparada con los comportamientos políticos". Compartió que su reacción fue irse a los Estados Unidos en los años sesenta y setenta, en_los años de aparición de la disciplina de la ciencia política, (y aclaró que en la Argentina fue un poco más tarde).

\section{Un divorcio que hemos pagado caro}

Guillermo O'Donnell pasó luego a explicar lo que sería el eje de su aporte en esa clase magistral: el divorcio entre ciencia jurídica y ciencia política. Con rela- 
ción al nacimiento de la ciencia política expuso: "que se fundó en un divorcio que desgraciadamente creo que hemos pagado caro. La ciencia política contemporánea en sus distintas versiones, sobre todo anglosajonas, pero también en Francia y por cierto al comienzo en Argentina, nació como reacción contra la ciencia jurídica. $\mathrm{El}$ argumento era que las ciencias jurídicas son demasiado formalistas, que eran aburridas y que nunca entraban a tratar de ver cómo la ley y la legalidad penetraban y constituían a la sociedad. En un estado hay relaciones de poder, y había que superar ese formalismo y dedicarse, "entre comillas" a los verdaderos temas, es decir: la política, el poder y la representación".

Manifestó inmediatamente, que también él había sido capturado por esa división, pero luego, cuando estudió los procesos de democratización, confesó que redescubrió el derecho. Expresó que volvió a estudiar, que leyó a otros autores, estudió constituciones contemporáneas; y como consecuencia se convenció rápidamente de "que no se puede pensar la democracia, y ni por cierto el estado, sin tener como una dimensión fundamental de ambos: la ley y el derecho". ${ }^{10}$

Remarcó que -aunque parezca obvio para algunos- no se puede entender la democracia, ni el estado, "sin tomar muy en serio a la ley y el derecho" y por eso entendía que la cuestión merecía algunas reflexiones y para profundizar en este problema elegía vincular los conceptos de democracia, estado y derecho. Enunció: "Comienzo por la democracia, más específicamente por una parte de la democracia: el régimen democrático. Según yo lo concibo el régimen democrático consiste en elecciones que son razonablemente limpias y competitivas; de la vigencia durante y después de las elecciones de ciertas libertades llamadas políticas". Enseguida pasó a explicar que estas libertades políticas en el fondo son derechos civiles, (como los de asociación, de reunión, de expresión) a los que habría que sumar los derechos positivos de participación en actividades políticas: votar e intentar ser elegido. Acorde con sus últimos aportes teóricos, manifestó que esos elementos combinados de elecciones y derechos definen un régimen político democrático. ${ }^{11}$

Su alocución incorporó, inmediatamente, el problema de la relación que vincula sujeto y derecho: la personalidad legal. Sobre ese soporte filosófico denunció que la ciencia política contemporánea -como consecuencia de su divorcio crítico de la ciencia jurídica- no advirtió algunos aspectos fundamentales tales como: "estos derechos, estas libertades de asociación, de expresión, los derechos positivos de participación son atributos de individuos que tienen personalidad legal, y que no existen solamente en un sentido legal sino que hacen posible que estos derechos no floten en el aire sino sean derechos "accionables" contra otros individuos y contra el estado".

Según lo expuso, si no se comprende la importancia de este problema, la libertad y los derechos son simplemente un papel blanco, y esto es porque "el papel del sujeto de la democracia, -la ciudadana o el ciudadano- solo puede ser tal si el sistema legal lo reconoce como persona legal. Este "re-conocimiento"12 de esta institución de la ciudadanía como tal, o sea como persona legal, es lo que permite que pueda anclarse en una sociedad un auténtico régimen democrático", 
reclamando que desgraciadamente la ciencia política olvidó que sin esa vigencia efectiva de la legalidad no hay régimen democrático y, según sus palabras textuales: (la ciencia política) "dejó flotando esta sinergia de ciudadanía y derecho en un espacio que no tiene ancla en la efectividad y en la exigibilidad que viene de un derecho democráticamente inspirado". Y lo reafirmó al expresar: "Es decir que si estos derechos y libertades no rigen, no son sancionados - no son bien sancionados- o son descuidados, entonces realmente el régimen, a pesar de la apariencia que viene de su origen electoral, se desnaturaliza y acaba siendo no democrático. Por supuesto, esta posibilidad de un pasaje de una democraticidad real a una falsa democraticidad exige e implica investigar permanentemente que esos derechos y libertades sean realmente efectivos y, como acabo de decir, que no se conviertan en letra muerta".

\section{Los autoritarismos electorales}

La referencia socio-histórica de su conferencia es el reconocimiento de la debilidad del estado democrático en América Latina, que en varias oportunidades se enfoca hacia los espacios en el interior de los estados nacionales, expresando en tal sentido: "para que exista un tipo de régimen auténticamente democrático tiene que haber por lo menos, lo que yo denomino un estado parcialmente democratizado; tema este que nos trae mucho a la actualidad nuestra, de América Latina y a nuestro país, es decir, estados que contienen todavía fuertes bolsones de prácticas y valores e incluso legislación autoritaria, pero, en tanto el régimen es democrático tienen aspectos de ser (estados) democráticos" ... "Yo creo que en nuestras democracias, -pobres democracias, en el sentido de limitaciones- estamos todavía muy lejos de llegar a ese tipo de estado, vivimos en el mejor de los casos en estados parcialmente democratizados en los cuales coexisten esta mezcla curiosa de estos bolsones (poderosos) y estos pedazos de libertades que nos permiten todavía hablar de un régimen democrático. Por supuesto, si no fuera así, el régimen habría dejado de ser democrático, se habría deslizado hacia el autoritarismo, aunque formalmente conserve, básicamente, la parodia, de haber elecciones competitivas... Esto, yo creo que ha llevado en América Latina y, no solo en América Latina, a lo que en la ciencia política se podrían llamar los autoritarismos electorales"; y cierra el tema diciendo "Estos regímenes electorales autoritarios están en el horizonte de nuestras deficientes democracias... (se trata) del problema de las democracias delegativas que tienen una tendencia muy peligrosa a deslizarse a ciertos autoritarismos". "13 "Creo con eso que las luchas por la democracia son en todas partes y todo el tiempo", afirmó.

\section{Leer correctamente a Weber}

"El estado de derecho es un aspecto fundamental de la democracia y es siempre un horizonte normativo". Con estas palabras Guillermo O'Donnell inscribió su teoría del estado democrático en una dimensión normativa, cuya vigencia se asocia a la calidad de la democracia y, esta, a la efectividad del sistema jurídico. ${ }^{14}$ Nos dijo: "no existe ni existirá jamás un perfecto estado de derecho donde todas 
las libertades y derechos se implementen y se vivan; pero es un horizonte normativo en el cual la realidad está más lejos o más cerca".

Invocando a Max Weber, indicó "que un estado es básicamente una unidad de base territorial que consiste en una serie de burocracias que ostentan el predominio del control legítimo de los medios de coerción en un territorio. Esto es correcto, realmente Weber dijo eso, pero por otro lado lo que esta literatura olvidó es que para el propio Weber no era menos importante en la caracterización del estado, el estado como una dimensión legal, el estado como una legalidad. La reducción que tiene el aparato del estado, que ha hecho una buena parte de la ciencia política contemporánea, olvidándose de la ley y el derecho, ha implicado una visión del estado como algo afuera y encima de la sociedad, sin ningún vínculo constitutivo con la sociedad; y por lo tanto, sin ninguna o muy pocas posibilidades, analíticas y empíricas, de trazar seriamente los vínculos posibles, negativos o positivos, entre el estado y las características políticas de la sociedad e inclusive la democracia".

Remarcó su insistencia en que debía recurrirse a Weber, pero en forma comple$\mathrm{ta}^{15}$, en la cual el estado es un conjunto de burocracias pero que "es también una legalidad, que ya no está afuera y encima de la sociedad sino que penetra en la sociedad, la teje, la entreteje y provee -cuando funciona razonablemente- el gran bien público de la previsibilidad de las relaciones sociales. Que cuando ese estado, además, se va acercando a un estado más propiamente democrático le provee también el enorme bien público de implementar, expandir y garantizar relaciones que son consistentes con la democracia, y que crean empoderamientos sociales que permiten que la sociedad se proponga avanzar en esta democracia con su propia fuerza". O'Donnell advierte que esta cuestión abre discusiones importantes, en las que habrá diferentes posiciones que van a influir en diferentes respuestas, pero deja sentado que "cualquier respuesta debe estar presidida por la conciencia muy aguda -que solo se puede dar la ciencia jurídica- ...cuando se habla de ciertas libertades y ciertos derechos".

\section{La necesaria reconciliación}

Ya, casi al final de la conferencia, Guillermo O’Donnell arengó diciendo que el problema del estado democrático nos concierne a todos, no obstante, conciente del auditorio que lo seguía atentamente aleccionó respecto de que esa responsabilidad les cabe especialmente a los juristas actuales y futuros, a quienes les pidió que recuerden a Von Ihering, "que persuasiva y tan elocuentemente reclamaba la lucha por el derecho", remarcando que este autor "decía e invocaba, que esa lucha debe darse desveladamente por la defensa de todo y cada derecho que existe, porque la suerte de una convivencia civilizada y democrática se juega en la vigencia de la lucha por cada derecho". Inmediatamente pidió la reconciliación en estos términos: "Esto en la conciencia jurídica, es por supuesto también, profundamente político"; advirtiendo a continuación "que en ese desandar estaba tratando de juntar dos lados, que por un tiempo han estado muy divorciados. Por el lado de la ciencia política recordar la implicación indispensable de ese régimen democrático en la ley y el derecho; por el lado de las ciencias jurídicas 
recordar que también, ha sido un tema bastante olvidado en la práctica habitual de bastantes años".

A su entender "este divorcio entre la ciencia política y la ciencia jurídica obedece a que realmente el concepto que adoptó la ciencia política del estado fue un concepto muy reduccionista". "Por eso mismo, y por esta condición del estado de ser también una dimensión constitutiva de legalidad, la lucha por la democracia es la lucha por el derecho, no solo luchas por la democratización de la sociedad son también luchas por la democratización del estado, es decir, son luchas por introducir valores democráticos, republicanos y de respeto humano en las instituciones estatales, otro terreno en el cual desgraciadamente a nuestros países nos queda muchos por hacer...". Y subrayó enfáticamente: "no solo por las razones teóricas sino porque son muy prácticas en la Argentina de hoy, las luchas por la democracia son necesariamente luchas por la legalidad estatal". Y a continuación remarcó que "este divorcio - que en los años sesenta y setenta era radical entre la ciencia política y la ciencia jurídica- había sido últimamente atenuado, pero se estaba muy lejos todavía de haber vuelto a la necesaria y mutua implicación. Reclamó entonces que "el divorcio se termine, que realmente los politólogos aprendamos mucho de la ciencia jurídica, que los juristas acepten nuestros conocimientos de ciertas realidades de la práctica del poder, que a veces escapa a la formulación de los textos legales o discursos jurisprudenciales".

Ya cerrando su alocución, exaltó el nacimiento de las carreras jurídicas en la Universidad Nacional de San Luis en "una cuna pluridisciplinaria". Remarcó "que debe darse una combinación de un excelente trayecto profesional con una impregnación y una mostración de esta ligazón de ese conocimiento profesional con estos valores democráticos, que, finalmente, son los mayores valores de respeto humano implicados por el reconocimiento de nuestra condición". Finalmente demandó a los jóvenes estudiantes no olvidar que las ciencias jurídicas deben ser siempre, "un camino fundamental para la construcción de una sociedad más democrática y más justa".

\section{Causa de honor}

Guillermo y Gabriela estuvieron unos días entre nosotros, visitando nuestra hermosa provincia de San Luis. Entonces pude comprobar que Guillermo era un formidable antropólogo político, buscando constantemente el sentido de lo instituido; hacía muchísimas preguntas, y reflexionaba con mucho sentido del humor. Todo parecía interesarle, y creo que eso tenía que ver con su inagotable fortaleza de desafiar lo conocido y buscar explicaciones a través del cuestionamiento constante, que se traduciría luego en su inagotable voluntad de producir conocimiento.

Corregía -por esos momentos- su último libro en el cual demostró nuevamente su condición de filósofo político capaz de ver los fenómenos más allá de lo evidente, buscando responder desde una concepción del sujeto. Todo esto tendría su correlato en la teoría de la agencia y en su demanda de que, para que un estado fuera democrático, debía hacer realidad la ciudadanía plena. 
Colegas -como él solía llamarnos- creo que Guillermo nos deja también otra lección fundamental: que la ciencia política no se trata solo de una importante producción de conocimiento, sino que implica promover su utilidad a través de la sabiduría.

Por ello comparto con el lector una reflexión que realicé al presentarlo en aquella conferencia. Recordé que honoris causa significa "causa de honor"; por lo tanto cuando nuestra Universidad otorgaba esta distinción era porque había una causa para honrar alguna forma de sabiduría. Esto es porque la sabiduría supone la existencia de un don -la inteligencia- unido a la responsabilidad ética en su uso. Por eso, en cada homenaje que hacemos a Guillermo honramos una mente brillante que producía ciencia política, pero además, honramos el cometido ético subyacente en toda su obra que demanda que todos los seres humanos tienen derecho a vivir en una democracia en la cual la vida merece ser vivida.

\section{Referencias}

1. Este texto fue reimpreso como Capítulo IX en O’Donnell, 1997.

2. Me refiero especialmente a G. Trocello (2008). A partir de sus comentarios a mi libro, iniciamos vía correo electrónico un rico intercambio de opiniones vinculado especialmente a su categoría de democracia delegativa.

3. En un e-mail me expresó: "San Luis me hizo recordar el discurso fascista de que en Italia los trenes llegaban en horario".

4. El 28 de diciembre de 2009 el Consejo Superior de la Universidad Nacional de San Luis, por Resolución $N^{\circ} 334$ resolvió otorgar al Doctor Guillermo O’Donnell el Grado Académico de Doctor Honoris Causa.

5. El 21 de agosto de 2009 el Consejo Superior había resuelto la creación de las carreras jurídicas de Abogacía y de pregrado de Procurador y Técnico Universitario en Asistencia Jurídica. El inicio de estas carreras debía ser en el primer cuatrimestre de 2010.

6. La Universidad Nacional de San Luis está en deuda respecto de esta publicación.

7. Guillermo O’Donnell usó generalmente el término ciencia política en singular y para la ciencia jurídica usó muchas veces el plural "ciencias jurídicas", tal como se denomina a las carreras en su conjunto en la Universidad Nacional de San Luis.

8. Agradezco especialmente a la Lic. Leticia Gutiérrez su aporte en la desgrabación de la conferencia.

9. La frase fue acompañada por el gesto de poner comillas con sus manos.

10. En esta instancia Guillermo O'Donnell hace alusión a que ya ha escrito varios trabajos y que saldría en breve un libro, que sería Democracia, agencia y estado. Teoría con intención comparativa.

11. Este tema lo desarrolló explícitamente en O’Donnell (2010) y en O’Donnell (2008).

12. Al enunciarlo poner hincapié en separar los vocablos.

13. Los ejemplos utilizados según sus palabras: "pasó con Fujimori en Perú, pasó con Putín en Rusia, creo que está pasando con Chávez en Venezuela y creo que Argentina no está vacunada contra este peligro".

14. En la conferencia adelantó lo que sería uno de los ejes de la teoría del estado que terminó de ajustar en O'Donnell (2010). También me expresó que este libro lo venía elaborando desde hacía aproximadamente veinte años, lo que coincide con lo expuesto en la conferencia al decir que sus preocupaciones sobre el divorcio entre ciencia jurídica y ciencia política aparecen al estudiar los procesos de democratización.

15. A su entender "este divorcio entre la ciencia política y la ciencia jurídica obedece a que realmente el concepto que adoptó la ciencia política del estado fue un concepto muy reduccionista" (en la conferencia que se comenta). 


\section{Bibliografía}

G. O’DONNELL (2010), Democracia, agencia y estado. Teoría con intención comparativa, Prometeo, Buenos Aires.

G. O’DONNELL (2008), “Acerca del Estado en América Latina contemporánea: Diez tesis para su discusión", en Conferencia Plenaria dictada en el XIII Congreso Internacional del CLAD sobre la Reforma del Estado y de la Administración Pública, Buenos Aires.

G. O'DONNELL (1997), Contrapuntos. Ensayos escogidos sobre autoritarismo y democratización, Buenos Aires, Paidós.

G. O’DONNELL (1993), “Acerca del estado, la democratización y algunos problemas conceptuales. Una perspectiva latinoamericana con referencia a países poscomunistas", en Desarrollo Económico, Vol. 33, $\mathrm{N}^{\mathrm{o}} 130$.

G. TROCELLO (2008), La manufactura de ciudadanos siervos: cultura política y regímenes neopatrimonialistas, Editorial Nueva Universidad, San Luis.

Recibido: 13/08/12. Aceptado: 30/08/12.

Gloria Trocello, "La necesaria reconciliación entre Ciencia Política y Ciencia Jurídica. Apuntes sobre la Clase Magistral de Guillermo O'Donnell: 'Acerca de la Ley, el Estado y la Democracia'". Revista Temas y Debates. ISSN 1666-0714, año 16, número 24, julio-diciembre 2012, pp. 31-39. 